\title{
Trajetórias de travestis de uma região de Mato Grosso, Brasil
}

\section{Trajectories of transvestites from a region of Mato Grosso, Brazil}

\author{
Lhays Emilly da Silva Moraes ${ }^{1}$, Vagner Ferreira do Nascimento ${ }^{2}$, \\ Ana Cláudia Pereira Terças-Trettel ${ }^{3}$, Juliana Benevenuto Reis ${ }^{4}$
}

\section{Resumo}

Essa investigação teve como objetivo conhecer as trajetórias de travestis de uma região de Mato Grosso, Brasil. Trata-se de um estudo exploratório e qualitativo. A coleta dos dados foi realizada de forma individual e áudio-gravada, por entrevista semiestruturada, com roteiro pré-testado, elaborado pelos próprios pesquisadores, contendo questões fechadas (aspectos sociodemográficos) e questões abertas (aspectos sobre saúde, hábitos sexuais, estilos de vida e vivências de travestis). A análise ocorreu sob a luz das três dimensões da Teoria do Reconhecimento Social. Verificou-se que a trajetória dessas travestis é marcada pela vivência de rompimentos e conflitos em espaços familiares, educacionais e profissionais. Apontam também dificuldades no processo de transição, casamento, adoção e uso do nome social. Esses aspectos influenciam as percepções de autoconfiança, autorrespeito e autoestima, que compõem as dimensões do reconhecimento social. Esse cenário urge a necessidade de ações que acolham e assistam as travestis, com a finalidade de promover e garantir a continuidade do acesso aos direitos e reconhecimento social.

Palavras-chave: Travestilidade; Reconhecimento social; Participação social.

\begin{abstract}
This investigation aimed to know the trajectories of transvestites in a region of Mato Grosso, Brazil. This is an exploratory and qualitative study. Data collection was performed individually and audio-recorded, through a semi-structured interview, with a pre-tested script, prepared by the researchers themselves, containing closed questions (sociodemographic aspects) and open questions (aspects about health, sexual habits, lifestyles and experiences of transvestites).
\end{abstract}

\footnotetext{
${ }^{1}$ Acadêmica de Enfermagem da Universidade do Estado de Mato Grosso (Unemat), Campus Universitário Tangará da Serra, Tangará da Serra, Mato Grosso, Brasil.

${ }^{2}$ Docente Adjunto da Universidade do Estado de Mato Grosso, Campus Universitário Tangará da Serra, Tangará da Serra, Mato Grosso, Brasil.E-mail: vagnernascimento@unemat.br

${ }^{3}$ Docente Adjunta da Universidade do Estado de Mato Grosso, Campus Universitário Tangará da Serra, Tangará da Serra, Brasil. Docente Permanente do Programa de Pós-graduação em Saúde Coletiva da Universidade Federal de Mato Grosso (UFMT), Campus Universitário Cuiabá, Cuiabá, Mato Grosso, Brasil.

${ }^{4}$ Doutoranda em Enfermagem Psiquiátrica na Escola de Enfermagem de Ribeirão Preto da Universidade de São Paulo (EERP-USP), Ribeirão Preto, São Paulo, Brasil. Docente Assistente da Universidade do Estado de Mato Grosso, Campus Universitário Tangará da Serra, Tangará da Serra, Mato Grosso, Brasil.
} 
The analysis took place in the light of the three dimensions of the Theory of Social Recognition. It was found that the trajectory of these transvestites is marked by the experience of disruptions and conflicts in family, educational and professional spaces. They also point out difficulties in the process of transition, marriage, adoption and use of the social name. These aspects influence the perceptions of self-confidence, self-respect and self-esteem, which make up the dimensions of social recognition. This scenario urges the need for actions that welcome and assist transvestites, with the aim of promoting and guaranteeing continued access to rights and social recognition.

Keywords: Transvestism; Social recognition; Social participation.

\section{Introdução}

Todas as pessoas podem ser percebidas social e culturalmente como homem ou mulher pelo comportamento, nome e/ou vestuário, comunicando uma expressão de gênero particular (SWAIN, 2019). A expressão de gênero parte do princípio de uma construção sócio-histórica, e vai além das determinações biológicas de uma pessoa em ser homem ou mulher (CANN; BROWN, 2019). Nesse contexto, as travestis correspondem a um grupo que possui uma expressão de gênero que difere da definição ocorrida no nascimento, transicionando para um papel de gênero distinto (KORPAISARN; SAFER, 2019).

Ser travesti é um processo contínuo. Este processo tem um começo com algumas etapas, 1) ao assumir para a família e para "a sociedade" sua orientação sexual, 2) quando começa se montar, 3) a intensificação da transformação, que inclui acesso e utilização de hormônios e procedimentos para feminilização, e 4) quando já se expressa como travesti propriamente (PELÚCIO, 2005). A travesti se expressa pela possibilidade de reinventar e ressignificar padrões sociais hegemônicos; todavia, muitas vezes são questionadas quanto à sua dignidade e participação na comunidade, esbarrando em obstáculos para acessar com liberdade e igualdade seus direitos (FERREIRA; SACRAMENTO, 2019). Destarte, é comum serem marginalizadas e desassistidas em suas necessidades, o que retarda a busca por serviços de apoio e cuidados (JENNINGS et al., 2019). Essa vulnerabilidade ampliada sobrevém das hostilidades permeadas de rejeição e julgamentos, o que interfere nas relações sociais, no ingresso e permanência no contexto familiar de origem, estudos/profissionalização e mercado de trabalho (ALMEIDA; VASCONCELLOS, 2018). Em virtude disso, cerca de $90 \%$ desse público encontram na prática da prostituição um meio de sobrevivência e socialização (ANTRA, 2018).

Essa somatória de fatores reduz a expectativa de vida das travestis, que atualmente é de 35 anos. Isso exemplifica, de modo geral, os enfrentamentos ético-políticos no cotidiano dessas pessoas, indicando a perversidade da sociedade, que reiteradamente naturaliza as diversas formas de violência contra as travestis, assim como a crescente de óbitos (DIAS; ARRUDA, 2021).

Aliada a essa vulnerabilidade, destaca-se como agravante para a saúde das travestis o comportamento de risco relacionado tanto às práticas sexuais que as expõe ao vírus da imunodeficiência humana (HIV) e a outras infecções sexualmente transmissíveis (IST) (ADELSON et al., 2019), como ao reflexo de um contexto de vida de violência, submissões e exclusões (YEUNG et al., 2019). Mas, parece que os serviços de saúde desconhecem a vulnerabilidade desse grupo, deixando de assistir integralmente e/ou acolher de forma humanizada (JENNINGS et al., 2019), mesmo com a existência da Política Nacional de Saúde Integral de Lésbicas, Gays, Bissexuais, Travestis e Transexuais (PNSILGBT), instituída no ano de 2011.

Esta política envolve as áreas de participação social, produção de conhecimento, cuidado, 
atenção e promoção à saúde. Entretanto, apesar de ter sido instituída para a defesa e fortalecimento da equidade em saúde e direitos da população LGBTQI+, sua aplicabilidade não tem ocorrido de forma efetiva, porquanto ações de monitorização da execução dessa política e a qualificação de gestores/profissionais para atuar na assistência a esse público ainda é ineficiente, o que torna a sua operacionalização fragilizada, sobretudo a nível local (SOUZA; HELAL, 2015).

Em localidades do interior do Brasil, as redes de apoio e serviço assistenciais atuam de forma mais tímida às travestis, e há vestígios de acolhimentos pouco humanizados, o que aumentam as chances de sofrimento e dificuldades de diversas ordens. No estado de Mato Grosso, por exemplo, ainda não se conhece a realidade das travestis. Diante disso, o estudo objetivou conhecer as trajetórias de travestis de uma região do interior de Mato Grosso, na perspectiva de dar visibilidade às suas experiências de vida.

\section{Método}

Trata-se de um estudo exploratório e qualitativo, com utilização do protocolo internacional Consolidated Criteria for Reporting Qualitative Research (COREQ), composto por 32 itens, que foram atendidos na íntegra, a fim de garantir o rigor metodológico. O estudo foi realizado em uma região do Centro-Sul do estado de Mato Grosso, a qual possui uma população estimada em 94.376 pessoas, predominância de atividades pecuaristas e uma extensão de aproximadamente $24.398 \mathrm{~km}^{2}$.

As participantes do estudo obedeceram a critérios de inclusão e exclusão. Foram incluídas maiores de 18 anos, aquelas que se denominaram travesti e que residiam nessa região há, no mínimo, seis meses. Foram excluídas travestis que não falavam o idioma português, em razão de a região possuir população boliviana.

Inicialmente foi realizada busca ativa para rastrear e identificar as possíveis participantes da pesquisa, com utilização da estratégia de snowball sampling, na qual a partir do contato com a primeira participante, esta indicaria outras que poderiam integrar o estudo. As participantes foram localizadas por meio de contato pessoal em ambientes próximos a postos de combustíveis e rodovia. Após aceite em participar da pesquisa, algumas optaram em realizar a coleta dos dados de imediato no mesmo local de abordagem, enquanto outras agendaram horário e local, normalmente no domicílio.

A coleta dos dados foi realizada de forma individual e áudio-gravada, através de entrevista semiestruturada, com roteiro pré-testado, elaborado pelos próprios pesquisadores, contendo questões fechadas (aspectos sociodemográficos) e questões abertas (aspectos sobre saúde, hábitos sexuais, estilos de vida e vivências de travestis). A amostragem do estudo foi não probabilística e intencional. $\mathrm{O}$ tamanho da amostra foi baseado no método de saturação, em que a interrupção das entrevistas ocorre por exaustão das informações pertinentes ao estudo e alcance dos objetivos (MINAYO, 2017).

Os dados empíricos produzidos nas entrevistas foram transcritos na íntegra e organizados com codificação alfanumérica, sendo "T" a representação das participantes, acrescido do número arábico que compõe o conjunto e determina a ordem das entrevistas. Para a análise do material, aplicou-se a análise de conteúdo à luz da Teoria do Reconhecimento Social, a qual se fundamenta em estudos de George Herbert Mead sobre formação de identidade, bem como de Georg W. Friedrich Hegel a respeito do reconhecimento social. A teoria é baseada no princípio de que a identidade da pessoa é determinada por meio de mecanismos do reconhecimento, que transitam pelas dimensões da autoconfiança, autorrespeito e autoestima (HONNETH, 2003). A escolha dessa teoria ocorreu pela estreita relação entre o reconhecimento social e as formas de enfrentamento dos obstáculos impostos na trajetória das travestis.

As linhas de análise foram compostas por pré-análise, exploração do material e o tratamento dos resultados (BARDIN, 2011). Após essa etapa, foram eleitas como categorias as três dimensões da 
própria Teoria do Reconhecimento Social (autoconfiança, autorrespeito e autoestima), organizadas em quadros.

O estudo respeitou todos os aspectos éticos em pesquisa com seres humanos, em conformidade com a Resolução 466/12, tendo aprovação pelo Comitê de Ética da Universidade do Estado de Mato Grosso (CEP/UNEMAT), com CAAE: 24338619.3.0000.5166 e parecer $n^{\circ}$ 3.779.704. Todas as participantes do estudo foram orientadas, receberam e assinaram o Termo de Consentimento Livre e Esclarecido (TCLE).

\section{Resultados}

Participaram do estudo sete travestis, com faixa etária entre 20 e 30 anos. A descoberta como travesti ocorreu entre oito e 17 anos, com apresentação à sociedade e família entre os 14 e 18 anos. A maioria é nascida e possui familiares nessa região. Relatam que possuem familiares com a mesma expressão de gênero (travesti), bem como com orientações sexuais distintas (gays e lésbicas), porém com pouca convivência, pois residem em outros municípios.

Predominou um público composto por pessoas solteiras, autodeclaradas pardas, católicas ou umbandistas, com ensino médio incompleto, trabalhando principalmente como profissionais do sexo (atendendo ambos os gêneros, com utilização pouco frequente de preservativos), tanto nas ruas como em ambiente virtual (encontros e viagens). Possuem renda mensal individual entre um e quatro salários mínimos (R\$ 1.045,00 a R\$ 4.180,00). Residem com amigas, geralmente outras travestis.

Dormem, em média, quatro a oito horas, tomam mais de dois banhos por dia e realizam comumente duas refeições (almoço e jantar). Não praticam nenhuma atividade física. As atividades de lazer se restringem às reuniões com os amigos, quando frequentam a casa da família e eventuais festas que ocorrem na região.

Buscam por serviços de saúde somente em situações de urgência ou emergência. Geralmente, recorrem à Unidade Básica de Saúde (UBS), onde possuem rotina de realização de testes rápidos para deteç̧ão de IST. Referem histórico de infecções dessa natureza, com tratamento e cura. Não possuem plano privado de saúde e negam uso de medicamentos de rotina ou controlados.

Utilizam hormônio há cinco anos, em média, com a combinação de anticoncepcional oral (ciclo 21) e injetável (a cada 15 dias), sendo administrados pelas próprias travestis, para fins de feminilização. Adquirem esses hormônios em farmácias, sem prescrição e acompanhamento profissional.

Fazem uso de substâncias psicoativas (SPA), predominantemente álcool, maconha e tabaco, e referem utilizar, na maioria das vezes, de forma conjunta (álcool e maconha). A primeira SPA usada foi álcool, que ocorreu entre 12 e 20 anos, após apresentação de amigas travestis, profissionais do sexo. Apresentaram a substância justificando efeitos importantes, como a permanência nas ruas por mais horas, disposição para aceitar diferentes parceiros, estar mais ativa e fazerem os programas com mais satisfação. Atualmente, a frequência de uso das substâncias é de três a quatro vezes por semana, com aquisição no próprio ambiente de trabalho. Sentem o desejo de parar o consumo, porém nunca buscaram tratamento. Desconhecem serviços/locais para esse cuidado terapêutico.

Todas já foram discriminadas em serviços de saúde, especialmente em relação ao nome social. Nas ruas, sofrem diversas formas de violência, desde olhares, apelidos constrangedores a agressões físicas. Apesar disso, declaram-se felizes.

\section{Autoconfiança}

No Quadro 1, as participantes relataram diversos fatores ligados ao fortalecimento e/ou diminuição de suas capacidades em enfrentar os distintos domínios da vida, que se referem ao acolhimento familiar, oportunidades de emprego, relacionamento nos grupos de convivência, a autoaceitação, desafio no processo de transição e a concepção da prática da prostituição. 
Quadro 1 - Distribuição das narrativas referentes à autoconfiança. Mato Grosso, Brasil. Abril de 2020.

\begin{tabular}{|c|c|c|}
\hline \multicolumn{3}{|c|}{ Narrativas } \\
\hline $\begin{array}{l}\text { [...] minha familia [dificuldade da } \\
\text { transição], porque no começo que } \\
\text { eu me assumi assim travesti, eles não } \\
\text { aceitaram de cara [...]. (T2). } \\
\text { A minha trajetória até aqui foi sem- } \\
\text { pre mais fácil, né, pelo apoio da } \\
\text { família [...]. (T4). } \\
\text { Vivi uma vida normal até os } 12 \text { anos, } \\
\text { por mais que eu sabia o que eu que- } \\
\text { ria, mas disfarçava bem, sabe? (T6). }\end{array}$ & $\begin{array}{l}\text { Eu sai de casa e recebi uma proposta } \\
\text { de uma amiga para me vestir de mu- } \\
\text { lher e descer pra BR, comecei a fazer } \\
\text { programa e gostei [...]. (T1). } \\
\text { Ser trans é libertar a gente mesmo } \\
\text { né, é viver o que a gente quer viver, } \\
\text { é fazer o que a gente quer fazer do } \\
\text { nosso jeito. (T4). } \\
\text { [...] é não ter vergonha de andar na } \\
\text { rua, não me esconder [...], sou bem } \\
\text { resolvida em relação a isso. (T5). }\end{array}$ & $\begin{array}{l}\text { Se vestir, se transformar, e chegar na } \\
\text { minha mãe [...] foi o mais dificil, en- } \\
\text { tendeu?, de enfrentar a realidade pra } \\
\text { ela, entendeu? (T1). } \\
\text { [...] depois [descoberta] que eu me } \\
\text { assumi eu me tornei uma pessoa me- } \\
\text { lhor. (T2). } \\
\text { Ser trans pra mim significa ser tudo } \\
\text { aquilo que eu sempre sonhei, é me ver } \\
\text { realizada como ser humano. (T3). } \\
\text { Quando entrei na minha adolescên- } \\
\text { cia eu comecei a me comportar como } \\
\text { gay, mas era uma coisa que eu não } \\
\text { me aceitava ainda [...], aí comecei a } \\
\text { me vestir de mulher. (T5). } \\
\text { Hoje ser assim é maravilhoso, vitori- } \\
\text { oso [...]. (T6). }\end{array}$ \\
\hline $\begin{array}{l}\text { Eu me sentia mal de não poder fazer } \\
\text { as partes das meninas na escola [...] } \\
\text { e eu tinha mais amigas, como até } \\
\text { hoje. (T1). } \\
\text { Ai foi bem complicada na escola } \\
\text { porque por eu ter que fazer certas } \\
\text { coisas com meninos e eu não gostava, } \\
\text { né [...]. (T5). } \\
\text { Mas, quando eu ia na escola [...] eu } \\
\text { comecei a fase de trans, nesse início } \\
\text { meus amigos não falavam comigo } \\
\text { mais [...]. (T6). }\end{array}$ & $\begin{array}{l}\text { Foi muito dificultoso, eu me descobri, } \\
\text { mas mesmo assim foi tudo muito es- } \\
\text { condido. [...] quando eu saí de casa, } \\
\text { ai comecei a me transformar. (T1). } \\
\text { Quando eu estava na escola eu não } \\
\text { era assumida não [...], então não } \\
\text { cheguei de sofrer nada. Quando eu } \\
\text { fui trabalhar, já fui pra prostituição } \\
\text { com } 14 \text { anos [...]. (T2). } \\
\text { [...] eu sempre tive boa produtivida- } \\
\text { de, só que eles não assinaram minha } \\
\text { carteira. E depois eu já nem quis } \\
\text { procurar nada. (T3). } \\
\text { Eu já trabalhei com [...] salão, mexer } \\
\text { com cozinha, então não foi dificil, } \\
\text { mas procurar um emprego fora desse } \\
\text { padrão eu nunca tentei [...]. (T4). } \\
\text { Eu tentei procurar, aí já olhavam } \\
\text { com outros olhos, né, aí eu larguei de } \\
\text { mão também, eu sabia que não ia dar } \\
\text { certo. (T5). }\end{array}$ & $\begin{array}{l}\text { Eu já era um gay muito afeminado } \\
\text { [...], todo mundo já sabia lá na es- } \\
\text { cola, e eu sempre tive essa facilidade } \\
\text { [...]. (T3). }\end{array}$ \\
\hline $\begin{array}{l}\text { Já sofri violência enquanto fazia pro- } \\
\text { grama [...]. Eu me sinto insegura, são } \\
\text { poucos que eu me sinto confortável. } \\
\text { (T1). }\end{array}$ & $\begin{array}{l}\text { [...] ganha dinheiro fácil, é tipo: } \\
\text { "poxa, hoje eu tô sem nada", ai é só } \\
\text { descer na rua e ganhar. (T1). } \\
\text { [...] é unir o útil ao agradável [...], é } \\
\text { a questão do dinheiro, é muito fácil, é } \\
\text { muito rápido. (T3). } \\
\text { A gente procura não chegar nesse } \\
\text { mundo, mas pelo fato de não con- } \\
\text { seguir a gente acaba se entregando } \\
\text { [...], é uma primeira opção que tem } \\
\text { pra gente pegar. (T5). } \\
\text { Não sinto segurança em me relacio- } \\
\text { nar não [...], quando você vai pra } \\
\text { programa ninguém sabe se você vol- } \\
\text { ta. (T6). }\end{array}$ & \\
\hline
\end{tabular}

Fonte: os autores. 


\section{Autorrespeito}

No Quadro 2, pode-se observar referência às experiências vivenciadas em relação aos direitos universais (como o uso de nome social, adoção e casamento), aos sentimentos ambivalentes de realização pessoal em sua transição, medo de julgamento e hostilidade da família e sociedade.

Quadro 2 - Distribuição de narrativas referentes ao autorrespeito. Mato Grosso, Brasil. Abril de 2020.

\begin{tabular}{|c|c|c|}
\hline \multicolumn{3}{|c|}{ Narrativas } \\
\hline $\begin{array}{l}\text { [...] por causa da minha família foi } \\
\text { muito difícil [descoberta], eu sempre } \\
\text { pensei muito neles, mais do que com } \\
\text { o mundo [...]. (T1). } \\
\text { No início o difícil foi a questão da } \\
\text { minha família [descoberta] [...], por } \\
\text { mim eu teria já começado a transição } \\
\text { mais nova, mas aí acabei adiando por } \\
\text { conta do meu pai [...]. (T3). } \\
\text { Ser trans é fazer o que a gente quer } \\
\text { fazer do nosso jeito [...], tendo os nos- } \\
\text { sos direitos como todas as pessoas. } \\
\text { [...] então eu tenho direito de casar e } \\
\text { adotar uma criança. (T4). } \\
\text { Foi a sociedade, por sentir medo de } \\
\text { ser julgada [...], de não ser aceita } \\
\text { pela sociedade [dificuldade da tran- } \\
\text { sição]. (T5). } \\
\text { Foi a minha familia [dificuldade da } \\
\text { transição], porque no ver dela ser } \\
\text { gay tudo bem [...], mas travesti não. } \\
\text { (T6). }\end{array}$ & $\begin{array}{l}\text { [...] não foi fácil [trajetória de vida], } \\
\text { se não é fácil para os héteros, para as } \\
\text { pessoas trans é ainda pior. (T3). } \\
\text { [...] antes de eu ter meu nome social, } \\
\text { era constrangedor, [...] como a gen- } \\
\text { te tá toda feminina, né, a gente fica } \\
\text { constrangida. (T4). } \\
\text { [...] já teve, assim [discriminação], } \\
\text { por olhares, e também pelo fato de } \\
\text { eu querer que me tratasse pelo nome } \\
\text { social. (T5). }\end{array}$ & $\begin{array}{l}\text { [...] nunca vi as unidades de saúde } \\
\text { realizando atividades voltadas para } \\
\text { nós, e isso aumenta o preconceito. } \\
\text { (T6). }\end{array}$ \\
\hline \multirow[t]{2}{*}{$\begin{array}{l}\text { [...] eu fui mandada embora de casa } \\
\text { porque eles não aceitavam me ver } \\
\text { vestida de mulher; ai a prostituição } \\
\text { acolhe. (T5). } \\
\text { [...] terminou a frase lacrando, dizen- } \\
\text { do que se eu fosse mudar ela ia me } \\
\text { levar, senão já ia me entregar para o } \\
\text { conselho tutelar porque ela não que- } \\
\text { ria. (T6). }\end{array}$} & $\begin{array}{l}\text { Foi dificil [transformação na fase } \\
\text { escolar], tive muito bullying, muito } \\
\text { preconceito com os colegas de escola } \\
\text { [...]. (T1). } \\
\text { Eu acabei deixando a faculdade por- } \\
\text { que precisei fazer só programa [...], o } \\
\text { mercado ainda é muito fechado. (T3). } \\
\text { [...] eu desisti [estudo] porque tinha } \\
\text { muitas piadinhas, conversinha de co- } \\
\text { lega e de professores [...], e só voltei } \\
\text { pra sala de aula depois de um ano. } \\
\text { (T4). } \\
\text { Era um pouquinho complicado, co- } \\
\text { meçou o preconceito e eu decidi lar- } \\
\text { gar a escola [...]. (T5). } \\
\text { Tentei procurar serviço em outros lu- } \\
\text { gares [...], mas nunca tive resposta, } \\
\text { acho que foi pelo meu jeito, né. (T6). }\end{array}$ & \\
\hline & $\begin{array}{l}\text { Se a gente deixar um curriculum num } \\
\text { lugar mais assim, eles vão olhar para } \\
\text { você [...] e já fala: "Ah, não tem } \\
\text { vaga”. (T2). }\end{array}$ & $\begin{array}{l}\text { Às vezes a gente acha pessoas que } \\
\text { quer pagar mais, tipo, "dou } 200 \text { reais } \\
\text { se você for sem camisinha”, e se for } \\
\text { cabeça de mente fraca aceita, né [...]. } \\
\text { (T2). }\end{array}$ \\
\hline
\end{tabular}




\begin{tabular}{|l|l|}
\hline Sempre vinha pessoas que iam procu- \\
rar emprego e falava de preconceito, \\
então eu nem procurava [...]. (T4). \\
{$[\ldots]$ a falta de emprego [levou a ser } \\
trabalhadora do sexo], porque o fato \\
da gente ser travesti a sociedade não \\
aceita, muitas portas se fecham pra \\
gente $[. .] ..(\mathrm{T} 5)$.
\end{tabular} \mid

Fonte: os autores.

\section{Autoestima}

No Quadro 3, enquanto para algumas travestis a sua trajetória de vida parece estar mais atrelada aos sentimentos negativos que sobrevém do rompimento do vínculo familiar e de amizades pós-transição, para outras participantes esse sentimento acontece de modo positivo, por estarem felizes, realizadas, seguras e prontas para conquistar novos espaços.

Quadro 3 - Distribuição de narrativas referentes à autoestima. Mato Grosso, Brasil. Abril de 2020.

\begin{tabular}{|c|c|}
\hline \multicolumn{2}{|c|}{ Narrativas } \\
\hline $\begin{array}{l}\text { Eu preferia ser uma mulher, porque trans sofre demais } \\
\text { [...]. (T1). } \\
\text { [..] eu me sentia uma pessoa triste, porque eu ficava } \\
\text { afastada da minha família [...], não falava com a minha } \\
\text { mãe e nem com a minha irmã. (T2). } \\
\text { Mulheres sempre recebem elogios em estarem bonitas, e } \\
\text { isso melhora muito a autoestima, com a gente isso é mais } \\
\text { entre nós mesmas. (T7). }\end{array}$ & $\begin{array}{l}\text { Antes da transição eu já me sentia uma pessoa feliz, mas } \\
\text { depois de transformada, eu me vejo no espelho e eu me } \\
\text { reconheço. (T3). } \\
\text { Ser travesti é ser uma pessoa que eu não preciso me es- } \\
\text { conder, é me sentir bem vestida de mulher. (T5). } \\
\text { Acho que aceitar nosso jeito, independentemente de qual- } \\
\text { quer coisa, nos dá força. (T7). }\end{array}$ \\
\hline $\begin{array}{l}\text { Internet, casa, brincando com as sobrinhas, essas coisas } \\
\text { assim, entendeu? [práticas de promoção da autoestima]. } \\
\text { (T1). } \\
\text { [...] minha mãe mora em outra cidade, aí às vezes vou } \\
\text { lá. Gosto de ficar mais com a familia mesmo [práticas de } \\
\text { promoção da autoestima]. (T2). } \\
\text { Pra mim foi super tranquilo [transformação na fase esco- } \\
\text { lar], por já chegar totalmente assim segura, ou as pessoas } \\
\text { falam com você ou nem se intrometem. (T3). } \\
\text { Ah, eu saio, mas assim, por conta do trabalho eu acho } \\
\text { que diversão é quando você tá vivendo bem [práticas de } \\
\text { promoção da autoestima]. (T4). } \\
\text { Ah, eu procuro sair de casa, [...] na casa dos meus } \\
\text { parentes, porque eu sou bem família também [práticas de } \\
\text { promoção da autoestima]. (T5). }\end{array}$ & $\begin{array}{l}\text { [...] nos meus } 25 \text { anos de idade me sinto uma pessoa vito- } \\
\text { riosa, que superou muitas coisas. (T1). } \\
\text { [...] me senti a mulher mais linda naquele dia [primeiro } \\
\text { contato com a prostituição], com uma perucona, salto } \\
\text { alto; para mim era aquilo que eu queria. (T6). }\end{array}$ \\
\hline
\end{tabular}

Fonte: os autores.

\section{Discussão}

A percepção da autoconfiança é uma forma de reconhecimento social adquirida principalmente por meio das relações inerentes ao afeto, amor e amizade, e está vinculada à capacidade da pessoa em ter confiança em suas próprias capacidades e emoções (ALMEIDA et al., 2019). Partindo dessa premissa, essa característica é formada e desenvolvida desde a infância, no seio familiar; 
a primeira instituição que o ser humano faz parte e que tem um papel essencial no fortalecimento dessa construção (COSTA; SOUZA, 2019).

Entre as participantes do estudo, a maioria denota a falta de apoio familiar, principalmente no início do processo de descoberta e apresentação à sociedade. Estudo em Santa Catarina, Brasil, corrobora ao afirmar que dentre os diversos desafios enfrentados pelas travestis em sua trajetória, o primeiro acontece nesse espaço social (SOUZA; PRADO, 2019). Além disso, a performance afeminada que já se emerge nessa fase culmina em expulsão de casa, e no seu afastamento desse convívio (MAGNO; DOURADO; SILVA, 2018).

Assim, o ambiente que deveria possuir essa dimensão fortalecida (ROSENKRANTZ et al., 2020), comumente não as acolhe (ANGONESE; LAGO, 2018). Dessa forma, ao terem que lidar com essa situação no início de sua transformação ainda no contexto familiar, manifestam baixa autoconfiança e se tornam mais vulneráveis a situações de violência (TAGLIATE; FRANCO, 2020).

$\mathrm{Na}$ escola, relatam que vivenciaram situações muito conflituosas em virtude da discriminação e exclusão, o que levou a interrupção precoce dos estudos. Tais características foram similares a outros estudos, ao indicar que essa realidade está intimamente ligada ao fato de começarem a exteriorizar suas particularidades de gênero (CRUZ; SANTOS, 2016), e por possuírem um reforço negativo quanto à autoconfiança, pois não conseguem lidar com esse ambiente e/ou outros grupos de convivência (BADGETT; WAALDIJK; RODGERS, 2019), por conseguinte não tendo motivação e nem solidez para seguir seus sonhos e ideias de vida (COSTA et al., 2020).

É importante destacar que nos últimos anos o espaço escolar vem recebendo olhares sobre a temática gênero, e ganhando importantes discussões, por muitas vezes, conflituosas, em razão de ideologias e questões culturais inerentes da população. E ainda que haja o crescimento de debates acerca do tema e suas relações, poucos adentram os conceitos de gênero, que segundo Scott (1990), pode ser pensado na conexão integral entre duas proposições: (1) o gênero como um elemento constitutivo de relações sociais baseadas nas diferenças percebidas entre os sexos e (2) o gênero como forma primária de dar significado às relações de poder.

Vale destacar que existem algumas políticas públicas voltadas ao público LGBTQI+ nessa seara, entre as quais destacam-se as ações educacionais Brasil Sem Homofobia (BRASIL, 2004), Plano Nacional de Educação em Direitos Humanos (PNEDH) (BRASIL, 2018a) e Plano Nacional de Promoção da Cidadania e Direitos Humanos de Lésbicas, Gays, Bissexuais, Travestis e Transexuais (PNDCDH-LGBT) (BRASIL, 2009). Nestas, há orientações ligadas à educação, para redução das desigualdades e discriminação, garantia de direito ao acesso e permanência em todos os níveis de ensino, promoção do respeito e reconhecimento da diversidade de gênero nesses espaços, incentivo à qualificação educacional e/ou profissional, formação de gestores na área da sexualidade e o fortalecimento da cidadania para o desenvolvimento pleno da educação dessas pessoas (BRASIL, 2004; BRASIL, 2009; BRASIL, 2018b).

Todavia, a inabilidade dessas políticas, principalmente em razão de um cenário ainda marcado pelo conservadorismo e de desmonte das próprias políticas públicas existentes interfere no alcance, aplicabilidade e fortalecimento de suas diretrizes, e isso é um dos fatores que têm promovido um sistema educacional pouco inclusivo (LACERDA; LARA, 2019), com intensificação da invisibilidade, pouca participação na sociedade, insegurança emotiva, e privação de vínculos entre os outros escolares, aspectos importantes para a construção e consolidação da autoconfiança (JESUS; VIEIRA; RODRIGUES, 2019). Dessa forma, ainda que as travestis sejam contempladas com esses marcos políticos, ainda é distante a efetividade e implementação dessas políticas em todo território brasileiro (SILVA; BRABO; SHIMIZU, 2019), com implicações diretas na permanência no ambiente escolar (FEITOSA, 2019), no ingresso no mercado de trabalho (ARAÚJO; VIEIRA, 2020) e em outras esferas sociais. 
Segundo as narrativas, a maioria não dispôs de oportunidades de emprego formal, encontrando na prostituição a opção para garantia de renda e sobrevivência, característica também identificada na literatura nacional (MEDEIROS; AMORIM; NOBRE, 2020) e em estudo realizado no Peru (BLITZ et al., 2019). Elas acrescentam ainda que esse trabalho as expõe a situações de medo e incerteza, pelo risco de vida (contato com desconhecidos e possibilidade de não retornarem ao lar), por aspectos econômicos (ganho insuficiente para se manterem) e por questões afetivas (dificuldade de aceitação do parceiro fixo e pelo medo de não conseguirem constituir uma família).

No âmbito profissional, aquelas que não possuem autoconfiança dificilmente se colocam em situações desafiadoras sem se importar com julgamentos (MAGNO et al., 2019). Estudo em uma região metropolitana de Minas Gerais, Brasil, identificou que os aspectos negativos vivenciados na prática da prostituição repercutem em prejuízos na busca por outras formas de trabalho, pois ficam condicionadas à insegurança e incerteza quanto à própria capacidade e reconhecimento de suas potencialidades (SOUZA et al., 2020).

Para a minimização dos impactos negativos na autoconfiança das travestis, destaca-se a importância da cooperação dos diversos atores sociais na assistência multidisciplinar e intersetorial (BUENO et al., 2020). Esse trabalho coletivo visa promover o fortalecimento de espaços de diálogo e assistência, preferencialmente na própria comunidade que ao mesmo tempo em que fornecerá apoio e cuidado, tende a diluir rótulos, caminhar para a igualdade e autoconfiança coletiva da população LGBTQI+ (CEATHA et al., 2019).

Ademais, na assistência à saúde é imprescindível o cuidado biopsicossial com foco na detecção das particularidades individuais que levam à fragilidade do reconhecimento social, uma vez que sem esse suporte há reflexos diretos na qualidade de vida e saúde dessa população (ROSA et al., 2019). O investimento no cuidado em saúde direcionado à promoção do crescimento e desenvolvimento dessas pessoas na comunidade é um dos pontos-chave para fomentar a autoconfiança (STEVENS; HAVERLY; POWELL, 2020).

Em relação à percepção do autorrespeito, caracterizado como o valor que o indivíduo atribui a si mesmo, concebido a partir do reconhecimento da sociedade sobre seus direitos e igualdade de condições morais (BACK; LUCERO, 2019), no estudo, embora se perceba considerável autorrespeito das travestis, o tratamento excludente e marginalizante de parte da sociedade diante de questões específicas do processo de transição, como a adesão ao nome social, casamento, adoção e conquista de espaços, interferem na totalidade do reconhecimento social. Pesquisa semelhante constatou que ao mesmo tempo em que tais questões integram direitos universais, ainda há muitas objeções e hostilidades (NAGAMINE, 2019).

Vários autores relatam que os problemas enfrentados em relação ao nome social expõem as travestis à humilhação, ao desrespeito e à frustração quanto às suas expectativas de reconhecimento (LAZCANO, 2019; SILVA; SANTOS, 2018). E pensar sobre tal direito é pensar também nos conflitos sociais que isso gera e nos impactos nos modos dessas pessoas se relacionarem na comunidade (PONTES; ROSATTI; REIS, 2020; SANTOS; JESUS, 2020; SILVA, 2019).

Além do nome social, a legislação existente prevê o casamento igualitário e a adoção, porém é uma realidade distante da maioria das participantes do estudo. Pesquisas realizadas no Brasil (DEUSDARÁ; ROCHA; ARANTES, 2019) e na Holanda (CHEN; OURS, 2020) indicam que essas pessoas, ao se verem com esse direito fragilizado e/ ou não aceito, quer seja por pessoas, grupos ou até mesmo serviços assistenciais, como, por exemplo, os serviços de saúde, seguem com a sensação de autorrespeito incompleto, uma vez que seu modo de ser e escolhas são impedidos e desvalorizados (CARVALHO; CARMO, 2019).

Em contrapartida, um aspecto importante identificado foi o fato de a percepção atual do autorrespeito ser positiva para algumas travestis. Essa característica distingue de algumas pesquisas, nas quais a feminilização do corpo é uma barreira 
persistente para o empoderamento dessa autonomia e autorreconhecimento (RO; OLSON, 2020; ALMEIDA; VASCONCELLOS, 2018; SANTOS FILHO; SOUSA, 2017).

Pesquisadores apontam que essa percepção positiva do autorrespeito das travestis ocorre, entre outros fatores, em decorrência do grau de estímulo que recebem em suas trajetórias de vida, estruturas de apoio e incentivo, que permitem a maior possibilidade de se autorreconhecer como dignas (GUILHON et al., 2019), e, sobretudo, de estarem preparadas para a busca e reafirmação de suas conquistas (SILVA; MACIEL; BRABO, 2019; TEIXEIRA; PORÉM, 2019). Esse feito fortalece o engajamento em movimentos sociais de militância LGBTQI+, com disposição para lutar por novos espaços na sociedade (MONTE; NASCIMENTO, 2020).

O autorrespeito é fundamental para a promoção de saúde dessas pessoas, já que esse componente do reconhecimento social permite que se autorrealizem socialmente, e possam ter vivências que tragam satisfação (SANTOS; MOREIRA; GOMES, 2020). Por isso, para além dos cuidados da dimensão físico-biológica, é necessário que os serviços e profissionais de saúde ao recebê-las deem atenção e valor aos seus modos de vida, até pela indissociabilidade destes aspectos na determinação do processo saúde-doença, e possíveis fragilidades que possam ampliar a vulnerabilidade a transtornos psicoemocionais (VENTURA et al., 2020).

Ainda que não mencionado pelas participantes, quanto à esfera jurídica e moral relacionada às travestis, existe uma iniciativa de política pública por meio do Programa Nacional de Direitos Humanos III (PNDH-3), aprovado no ano de 2009, que fomenta a consolidação das redes de proteção e valorização referente aos direitos humanos de vários grupos sociais, dos quais as travestis estão inclusas (BRASIL, 2009). Ao contrário do Brasil, poucos países latino-americanos possuem políticas e leis que regulam tais direitos (BARRIENTOS, 2016).

No contexto da região deste estudo, o pouco acesso ou conhecimento das travestis sobre direitos e/ou participação efetiva na comunidade pode ser reflexo das poucas iniciativas de instituições e/ ou movimentos de militância com essa bandeira social, comparado a grandes centros (PEREIRA, 2020), baixo interesse de gestores e sociedade na discussão das relações de gênero (BATISTA et al., 2018), e espaço reduzido para pautas que integram as necessidades das travestis (OLIVEIRA et al., 2020). Nesse aspecto, ainda que a Política Nacional de Promoção da Saúde (PNPS), instituída no ano de 2006, proponha a promoção da equidade quanto às condições no modo de viver das pessoas, incluindo a valorização da diversidade (PETERMANN; KOCOUREK, 2020), de acordo com as narrativas das travestis não há atividades dos serviços de saúde nessa direção.

Apesar de existirem políticas públicas no Brasil que contemplam esse grupo, evidencia-se que houve significativos retrocessos nos últimos anos, visto que as iniciativas governamentais, além de não acompanharem as demandas e necessidades da população (MACHADO; GRAUPE; LOCKS, 2020), também não têm assegurado a efetividade e continuidade dos programas já existentes, expressando até mesmo perseguições e ameaças aos programas sociais. Essa circunstância vivenciada atualmente contribui para a idealização da cultura de invisibilidade e violência social (GONZAGA; GALLAS, 2019).

Em Mato Grosso, a última ação direcionada ao público LGBTQI+ foi a criação no ano de 2012 do Grupo Estadual de Combate à Homofobia (GRECO), que é vinculado à Secretaria de Estado de Segurança Pública (SESP). Sua origem se deu com o objetivo de fomentar a elaboração de políticas públicas relacionadas à segurança pública, contudo, tal ação recebe pouco apoio governamental se comparada a outras frentes de trabalho assistenciais e voltadas à proteção de direitos humanos (ARAGUSUKU; LOPES, 2019).

Sobre a percepção da autoestima, que compreende um constructo de senso de valor internalizado de cada indivíduo (SANTOS; MORALES, 2020), ou seja, a valorização que é atribuída a si mesmo (SCHOEPS et al., 2019), aquelas que possuem autoestima elevada são mais proativas, têm 
mais facilidade em superar desafios que emergem no percurso da vida e em lidar com os conflitos internos (MONTEIRO; GUIMARÃES, 2019). Por outro lado, a baixa autoestima é refletida em dificuldades em relacionamento interpessoal e tomada de decisão oportuna (CASTRO; LOPES; MONTEIRO, 2020).

No estudo, observou-se que a autoestima de algumas travestis está associada com os sentimentos negativos de suas trajetórias de vida, principalmente pelo rompimento do vínculo familiar e de grupos de convivência (GUALDA; LACUNZA, 2020). Estudo realizado com 203 pessoas trans brasileiras identificou que a família tem papel decisivo no processo de transição, o que reverte em níveis mais satisfatórios de autoestima (SILVA; SANTOS, 2018), assim como observado em uma pesquisa na Indonésia (STARKI; AMIN, 2019). Ainda assim, vale salientar que cada país possui um contexto cultural distinto, o que se traduz em diferentes modos de tratamento e acesso a direitos.

Conforme as narrativas, o desvelar de suas singularidades, especialmente no primeiro contato com acessórios femininos e na sua constituição como travesti, é um momento de felicidade, sentimento que para algumas é mecanismo de fortalecimento. Pesquisas referem que o fortalecimento do "Eu" tem estreita relação com a autoestima, o que repercute na percepção de satisfação que as travestis possuem sobre si, de suas características e autoimagem (ROVAI, 2019; SILVA; SANTOS, 2018; BOZANI et al., 2019). Em compensação, a percepção de autoestima varia cotidianamente, por fatores internos e externos, deixando-as suscetíveis ao embotamento, isolamento social, depressão, desequilíbrio das funções fisiológicas, dificuldades para ingressar e manter relações sociais, e outros comprometimentos na saúde e em seus projetos de vida (OSORIO; GÓMEZ, 2020; SILVA et al., 2020).

E no momento em que essas pessoas apresentam uma autoestima fragilizada há interferência no seu reconhecimento social (DURÁN, 2020), visto que é por meio dela que as pessoas podem afirmar e enaltecer suas particularidades no meio social, isto é, de se reconhecer com estima por suas características próprias (HAMEL; BOANOVA, 2020). Em contraponto, aniquilar o potencial de cada uma frente à sua forma singular de viver a travestilidade apresenta como um forte conduto à violência psicológica (MUGABE, 2019), a qual é considerada uma das manifestações de violência mais vivenciadas pelas travestis, que se dá por meio de ameaças, constrangimentos, agressões físicas, oposição quanto à mudança de comportamento, discriminação e impedimento à socialização (FORMENTO; ALMEIDA, 2020).

Nesse aspecto, as políticas públicas de gênero partem da premissa de que as instituições estatais são partícipes da construção política e social dessas pessoas e, portanto, devem combater a iniquidade e a desigualdade nas relações sociais. Essas políticas se desenvolvem em contexto amplo, buscando aperfeiçoar e promover melhor a qualidade de vida para todos por intermédio do pleno exercício da cidadania (BANDEIRA; ALMEIDA, 2013).

Outra característica observada entre as travestis participantes do estudo foi a baixa inserção em atividades de lazer. Essa restrição no modo de vivenciarem o lazer, segundo alguns autores, se deve ao fato de não se sentirem plenamente livres para comunicarem suas singularidades em todos os espaços (SILVA; ISAYAMA, 2020). Sabe-se, porém, que essa prática é indispensável no desenvolvimento da autoestima (WEDIG et al., 2020); para a cidadania, por envolver a pessoa como parte de uma coletividade (BARBOSA et al., 2020; GUITIERRES; LORDELLO, 2020; PRETO et al., 2020; SANTOS; MARTINELLI, 2019) e por oportunizar espaços de convívio e encontros, o que favorece o bem-estar e a saúde (MANCINI; COSTA; GUILEN, 2020).

$\mathrm{Na}$ PNSI-LGBT há um realce pontual da autoestima, particularmente em relação à inserção de ações educativas em rotinas de serviços de saúde (PIRATELLI FILHO et al., 2019), mas se esbarra em práticas de educação em saúde pouco inclusivas e que raramente trabalham as temáticas de interesse para todos os públicos (KESSLER; FACCHINI, 2018). 
Logo, embora seja preconizada a discussão e promoção de atividades de educação em saúde na área, há pouco preparo dos profissionais para atuar junto às necessidades desse grupo, voltandose quase que exclusivamente para as doenças infectocontagiosas (ALBUQUERQUE; BOTELHO; RODRIGUES, 2019). A falta de sensibilidade para assistir as travestis prejudica a integralidade do cuidado, ao desconsiderar aspectos importantes da vulnerabilidade das travestis, como seus conflitos, sofrimentos diários, relações sociais e suas condições de vida (PAULINO; RASERA; TEIXEIRA, 2019).

Nessa perspectiva, desenvolver tais ações a respeito da autoestima exige que os profissionais ofereçam uma assistência humanizada. Nesse sentido, a Política Nacional de Humanização (PNH), criada em 2003, dentre outros pontos fomenta o fortalecimento de práticas assistenciais que valorizam as dimensões subjetivas e necessidades específicas frente ao sexo e gênero. Apesar disso, na prática não há mudanças significativas ao longo desses anos no modo de cuidar e assistir as travestis (MORAES; SILVA, 2020).

Nesse panorama, entende-se que o processo saúde-doença das travestis se relaciona, principalmente, com aspectos que vão desde as doenças físicas (LOVISON et al., 2019) até o reconhecimento intersubjetivo e o desenvolvimento social (LACERDA; LARA, 2019). Dessa forma, assegurar saúde e qualidade de vida é também promover o reconhecimento de sua imputabilidade moral, natureza afetiva, capacidades, autonomia e autorrealização (NAGAMINE, 2019), assim como a saúde mental e laboral.

Entretanto, nos últimos anos, o rompimento desses aspectos vem determinando agravos à saúde, entre eles a ocorrência de suicídios e outras fatalidades nessa população (HEISE et al., 2019). De acordo com dados atuais, o Brasil lidera mundialmente o número de mortes de travestis e transexuais (GALRÃO; CARVALHO, 2020), incluindo o crescimento das taxas de suicídio e tentativas de suicídio (BAÉRE; CONCEIÇÃO, 2018).
Também estão entre as estatísticas de progressão os homicídios, sendo que no primeiro bimestre de 2020 o País teve um aumento de 90\% destes casos quando comparado ao mesmo período do ano anterior (ANTRA, 2020).

Essa intolerância, que viola os direitos de exercer as singularidades, quando não interrompe a trajetória de vida dessas travestis, reflete na capacidade dessas pessoas frente à descoberta e exercício do autocuidado (VOSVICK; STEM, 2019). Nesse sentido, estudo realizado em Pernambuco, Brasil, evidenciou que diversos agravos à saúde de pessoas trans se relacionam às limitações na prática do autocuidado, especialmente em relação aos procedimentos estéticos, perfil de alimentação, comportamento sexual e consumo de drogas, normalmente pelo pouco conhecimento que possuem sobre estilos de vida mais saudáveis e/ou desassistência quanto ao atendimento às suas necessidades (ANDRADE et al., 2018).

Dessa maneira, viver essa vulnerabilidade, muitas vezes sem a intervenção das equipes multiprofissionais, colocam as travestis simultaneamente na condição de adoecimento progressivo e distanciamento do reconhecimento social (VEIGA; ROMANINI, 2017). Diante disso, os profissionais devem acolher e dar suporte/preparo emocional para a pessoa e seus familiares, bem como oferecer informações/orientações sobre a travestilidade e a transexualidade (GONÇALVES; FRANCO, 2019). Para isso, é fundamental fortalecer a intersetorialidade frente às questões de gênero para o apoio, principalmente na fase de transição (período que a autoestima começa a ser consolidada), e a elaboração de programas de educação permanente para profissionais do serviço social, educação e saúde, de modo a promover o conhecimento sobre gênero e prepará-los no acompanhamento de crianças/adolescentes/jovens que apresentem essas singularidades (GUTIERRES; LORDELLO, 2020).

Especificamente, os profissionais da saúde devem possuir durante sua formação disciplinas que apresentem as relações de gênero como enfoque, para romper rótulos, facilitar a compreensão 
das dificuldades enfrentadas nas diversas trajetórias de vida e serem multiplicadores/incentivadores de ambientes com maior respeito e igualdade (QUADRADO; FERREIRA, 2019). No entanto, muitas instituições de ensino no Brasil não proporcionam espaços para discussões e vivências nesse sentido, estratégias metodológicas para trabalhar esses temas e docentes com aporte teórico-didático ou interesse à temática (ZANI; TERRA, 2019). Essa lacuna formativa dos profissionais leva a uma prática assistencial discriminatória, pouco inclusiva e restrita a aspectos biomédicos, não considerando a integralidade e trajetórias de vida dessa população (GONÇALVES et al., 2019). A isso chamamos de transfobia institucional, sempre somada às transfobias pessoais, sociais e familiares.

\section{Considerações finais}

$\mathrm{O}$ estudo evidenciou que a trajetória das travestis dessa região é marcada principalmente pela vivência de rompimentos e conflitos em espaços familiares, educacionais e profissionais. Apontam, também, dificuldades no processo de transição, casamento, adoção e uso do nome social. Esses aspectos, por sua vez, influenciaram de modo negativo nas percepções de autoconfiança, autorrespeito e autoestima, que compõem as dimensões do reconhecimento social. Identificou-se, porém, aspectos positivos quanto ao autorrespeito e à autoestima para algumas travestis, apontando que apesar das negações e violações experienciadas, alguns espaços/relações e a autopercepção dessas pessoas levam também à possibilidade de autovalorização e enaltecimento do seu "eu".

A trajetória dessas travestis vem expondo à marginalização, intolerância e sensação de perda da dignidade, o que aumenta as dificuldades no enfrentamento dos obstáculos ainda existentes em relação à diversidade de gênero na sociedade. Prejuízos nessas dimensões sociais vêm prejudicando a saúde dessas travestis, já que as políticas públicas direcionadas à população LGBTQI+ no Brasil possuem pouco fomento, fragilidades de implementação, pequena adesão e efetividade.
Esse panorama suscita reflexões e futuros encaminhamentos, em especial aos profissionais da educação, saúde e assistência social, a respeito da necessidade de projetos e ações intersetoriais que acolham, assistam e sejam apoio contínuo para a garantia de acesso aos direitos e reconhecimento social das travestis. Para isso, devem também ser repensados as estratégias de promoção do autocuidado e o estabelecimento de unidades especializadas para demandas especiais em relação ao gênero.

Dentre as limitações do estudo, pode-se destacar a forma de recrutamento e o local escolhido pelas participantes, pois coincidiu com o ambiente de trabalho (vias públicas), circunstância que pode ter influenciado as entrevistas. Ainda assim, todas as participantes tiveram a oportunidade de manifestar livremente suas inquietações, dando visibilidade aos seus enfrentamentos diários que causam risco ao seu reconhecimento social e à sua integridade.

\section{Referências}

ADELSON, M. D. ; WALKER-CORNETTA, E.; KALISH, N. LGBT Youth, Mental Health, and Spiritual Care: Psychiatric Collaboration With Health Care Chaplains. Journal of the American Academy of Child \& Adolescent Psychiatry, Hagerstown, v. 58, n. 7, p. 651-655, 2019. Doi: https://doi.org/10.1016/j.jaac.2019.02.009. Disponível em: https://bit.ly/3y5hn6T. Acesso em: 30 out. 2020 .

ALBUQUERQUE, M. R. T. C.; BOTELHO, N. M.; RODRIGUES, C. C. P. Atenção integral à saúde da população LGBT: Experiência de educação em saúde com agentes comunitários na atenção básica. Revista Brasileira de Medicina de Família e Comunidade, Rio de Janeiro, v. 14, n. 41, p. 1-11, 2019. Doi: https://doi.org/10.5712/ rbmfc14(41)1758. Disponível em: https://bit. ly/2UL4kcp. Acesso em: 30 out. 2020.

ALMEIDA, C. B.; VASCONCELLOS, V. A. Transexuais: transpondo barreiras no mercado de trabalho em São Paulo? Revista Direito GV, São Paulo, v. 14, n. 2, p. 302-333, 2018. Doi: https://doi. org/10.1590/2317-6172201814. Disponível em: https://bit.ly/2UUE3c1. Acesso em: 30 out. 2020. 
ALMEIDA, R. G. S.; MAZZO, A.; MARTINS, J. C. A.; JORGE, B. M.; SOUZA JÚNIOR, V. D.; MENDES, I. A. C. Autoconfiança no cuidado ao paciente crítico: pré e pós-intervenção simulada. Revista Brasileira de Enfermagem, Brasília, v. 72, n. 6, p. 1696-1701, 2019. Doi: https://doi. org/10.1590/0034-7167-2018-0758. Disponível em: https://bit.ly/3AdCSVd. Acesso em: 30 out. 2020 .

ANDRADE, C. A. A.; LOUREIRO, A. R.; LIMA NETO, E. R.; VASCONCELOS, E. M. R.; ARAÚJO, E. C. Requisitos de autocuidado de mulheres transexuais em uso de hormônios sexuais segundo teoria de OREM. Cogitare Enfermagem, Curitiba, v. 23, n. 3, p. 2018. Doi: http://dx.doi. org/10.5380/ce.v23i3.55748. Disponível em: https://bit.ly/3jwUcyB. Acesso em: 30 out. 2020.

ANGONESE, M.; LAGO, M. C. S. Família e experiências de parentalidades trans. Revista de Ciências Humanas, Florianópolis, v. 52, e57007, p. 1-18, 2018. Doi: https://doi.org/10.5007/21784582.2018.e57007. Disponível em: https://bit. 1y/2Tj6XBZ. Acesso em: 30 out. 2020.

ANTRA - ASSOCIAÇÃO NACIONAL DE TRAVESTIS E TRANSEXUAIS. Assassinatos de pessoas trans voltam a subir em 2020. Rio de Janeiro, 2020. Disponível em: https://bit. 1y/3w5XcEv. Acesso em: 30 out. 2020.

ANTRA - ASSOCIAÇÃO NACIONAL DE TRAVESTIS E TRANSEXUAIS. Mapa dos assassinatos de travestis e transexuais no Brasil em 2017. Rio de Janeiro, 2018. Disponível em: https:// bit.ly/3qzYBC3. Acesso em: 23 ago. 2020.

ARAGuSUKU, H. A.; LOPES, A. S. Políticas públicas e cidadania LGBT em Mato Grosso: uma década de avanços e retrocessos (20072017). Sexualidad, Salud y Sociedad, Rio de Janeiro, n. 29, p. 147-171, 2019. Doi: https:// doi.org/10.1590/1984-6487.sess.2018.29.07.a. Disponível em: https://bit.ly/3x9wc8G. Acesso em: 30 out. 2020.

ARAÚJO, T. E. V.; VIEIRA, M. C. Território da comunidade travesti no centro de Teresina-PI. Diversitas Journal, Alto Cruzeiro Arapiraca, v. 5, n. 1,p.315-322,2020. Doi:https://doi.org/10.17648/ diversitas-journal-v5i1-1063. Disponível em: https://bit.ly/3weS51L. Acesso em: 30 out. 2020.
BACK, R.; LUCERO, E. A luta por reconhecimento: base para uma educação voltada à construção da cidadania? O que nos faz pensar, Rio de Janeiro, v. 28 , n. 45 , p. 369-385, 2019. Disponível em: https://bit.ly/3jm1CVc. Acesso em: 30 out. 2020.

BADGETT, M. V. L.; WAALDIJK, K.; RODGERS, Y. V. M. The relationship between LGBT inclusion and economic development: Macro-level evidence. World Development, New York, v. 120, p. 1-14, 2019. Doi: https://doi.org/10.1016/j. worlddev.2019.03.011. Disponível em: https://bit. 1y/3h0wXLw. Acesso em: 30 out. 2020.

BAÉRE, F.; CONCEIÇÃO, M. I. G. Análise da produção discursiva de notícias sobre o suicídio de LGBTs em um jornal impresso do Distrito Federal. Revista Ártemis, João Pessoa, v. 25, n. 1, p. 74-88, 2018. Doi: https://doi.org/10.22478/ufpb.18078214.2018v25n1.37229. Disponível em: https:// bit.ly/3A8f9FM. Acesso em: 30 out. 2020.

BANDEIRA, L. M.; ALMEIDA, T. M. C. A transversalidade de gênero nas políticas públicas. Revista do CEAM, Brasília, v. 2, n. 1, p. 35-46, 2013. Disponível em: https://bit.ly/2Uedyxv. Acesso em: 30 out. 2020.

BARBOSA, V. D.; NÓBREGA,W. F. S.; SILVA, G. C. B.; MELO NETO, O. N.; COSTA, L. H. D.; FEITOSA, F. S. Q. Adote um sorriso: o resgate da autoestima de idosos institucionalizados. Revista Conexão, Ponta Grossa, v. 16, e2014331, p. 1-7, 2020. Doi: https://doi.org/10.5212/Rev. conexao.v.16.14331.030. Disponível em: https:// bit.ly/364mXKZ. Acesso em: 30 out. 2020.

BARDIN, L. Análise de conteúdo. São Paulo: Edições 70, 2011.

BARRIENTOS, J. Situación social y legal de gays, lesbianas y personas transgénero y la discriminación contra estas poblaciones en América Latina. Sexualidad, Salud y Sociedad, Rio de Janeiro, v. 15, n. 22, p. 331-354, 2016. Doi: https:// doi.org/10.1590/1984-6487.sess.2016.22.15.a. Disponível em: https://bit.ly/3y4r45v. Acesso em: 30 out. 2020 .

BATISTA, G. F.; DRUMOND, E. F.; FONSECA, M. C.; MODENA, C. M. Representações de gênero pelos gestores locais de saúde. Saúde redes, Porto Alegre, v. 4, n. 2, p. 51-58, 2018. Doi: https:// doi.org/10.18310/2446-4813.2018v4n2p51-58. 
Disponível em: https://bit.ly/3x7brKK. Acesso em: 30 out. 2020.

BLITZ, A. L. T.; HERRERA, M. C.; CALVO, G. M.; VARGAS, S. K. CACERES, C. F.; KLAUSNER, J. D.; KONDA, K. A. Venue-Based HIV-Testing: An Effective Screening Strategy for High-Risk Populations in Lima, Peru. AIDS and Behavior, Storrs, v. 23, n. 4, p. 813-819, 2019. Doi: https://doi.org/10.1007/s10461-018-2342-8. Disponível em: https://bit.ly/3jEDFJ1. Acesso em: 30 out. 2020.

BOZANI, V.; DRYDAKIS, N.; SIDIROPOULOU, K.; HARVEY, B.; PARASKEVOPOULOU, A. Workplace positive actions, trans people's selfesteem and human resources' evaluations. International Journal of Manpower, n. 12732, 2019. Disponível em: http://ftp.iza.org/dp12732.pdf. Acesso em: 30 out. 2020 .

BRASIL. Ministério da Saúde (MS). Conselho Nacional de Combate à Discriminação. Brasil sem Homofobia: programa de combate à violência e à discriminação contra GLTB e promoção da cidadania homossexual. Brasília: Ministério da Saúde, 2004.

BRASIL. Ministério dos Direitos Humanos. Comitê Nacional de Educação em Direitos Humanos. Plano nacional de educação em direitos humanos: PNEDH. Brasília: Ministério da Saúde, 2018. Disponível em: https://bit.ly/30Ag30B. Acesso em: 30 out. 2020 .

BRASIL. Ministério da Saúde (MS). Secretaria de Vigilância em Saúde. Secretaria de Atenção à Saúde. Política Nacional de Promoção da Saúde: PNPS. Brasília: Ministério da Saúde, 2018.

BRASIL. Secretaria Especial dos Direitos Humanos (SEDH). Plano Nacional de Promoção da Cidadania e Direitos Humanos de Lésbicas, Gays, Bissexuais, Travestis e Transexuais. Brasília: SEDH, 2009.

BUENO, N. S.; GOMES, A. J. R.; CARVALHO, C. S.; TANIMITSU, L. Y. R.; GRACIANO, M. V. V.; OLIVEIRA, S. R. R.; POLETTI ZANI, $\mathrm{H}$. Os desafios no acesso à saúde da comunidade de Lésbicas, Gays, Bissexuais, Travestis e Transexuais no Brasil: uma revisão integrativa.
Brazilian Journal of Health Review, São José dos Pinhais, v. 3, n. 4, p. 8524-8538, 2020. Doi: https:// doi.org/10.34119/bjhrv3n4-104. Disponível em: https://bit.ly/3jpoF1c. Acesso em: 30 out. 2020.

CANN, E. M.; BROWN, M. Education and pra/ ctice developments: Addressing the psychosocial concerns and support needs of LGBT+ people. Nurse Education Today, Edinburgh, v. 82, p. 1520, 2019. Doi: https://doi.org/10.1016/j.nedt.2019. 08.008. Disponível em: https://bit.ly/3x9wzzV. Acesso em: 30 out. 2020.

CARVAlHO, A. P. N.; CARMO, G. M. O instituto do casamento revisitado sob os moldes da constitucionalização do direito civil brasileiro. Revista Jurídica Cesumar, Maringá, v. 19, n. 2, p. 479-496, 2019. Doi: https://doi.org/10.17765/ 2176-9184.2019v19n2p479-496. Disponível em: https://bit.ly/3dmweSH. Acesso em: 30 out. 2020.

CASTRO, N. B.; LOPES, M. V. O; MONTEIRO, A. R. M. Baixa Autoestima Crônica e Baixa Autoestima Situacional: uma revisão de literatura. Revista Brasileira de Enfermagem, Brasília, v. 73, n. 1,p. 1-9,2020. Doi: https://doi.org/10.1590/00347167-2018-0004. Disponível em: https://bit. ly/3h5Fj10. Acesso em: 30 out. 2020.

CEATHA, N.; MAYOCK, P.; CAMPBELL, J.; NOONE, C.; BROWNE, K. The power of recognition: a qualitative study of social connectedness and wellbeing through LGBT sporting, creative and social groups in Ireland. International Journal Environmental Research and Public Health, Basel, v. 16, n. 19, p. 1-18, 2019. Doi: https:// doi.org/10.3390/ijerph16193636. Disponível em: https://bit.ly/3ygNQXU. Acesso em: 30 out. 2020.

CHEN, S.; OURS, J. C. V. Symbolism matters: The effect of same-sex marriage legalization on partnership stability. Journal of Economic Behavior \& Organization, Amsterdam, v. 178, p. 44-58, 2020. Doi: https://doi.org/10.1016/j.jebo.2020.07.021. Disponível em: https://bit.ly/3ye5Zpr. Acesso em: 30 out. 2020.

COSTA, E. L.; SOUZA, J. R. S. Família e escola: as contribuições da participação dos responsáveis na educação infantil. Revista Khora, Rio de Janeiro, v. 6, n. 7, 2019. Disponível em: http://site.feuc.br/ khora/index.php/vol/article/view/166. Acesso em: 30 out. 2020. 
COSTA, R. R. O.; MEDEIROS, S. M.; COUTINHO, V. R. D.; MAZZO, A.; ARAÚJO, M. S. Satisfação e autoconfiança na aprendizagem de estudantes de enfermagem: ensaio clínico randomizado. Escola Anna Nery, Rio de Janeiro, v. 24, n. 1, p. 1-9, 2020. Doi: http://dx.doi.org/10.1590/21779465-EAN-2019-0094. Disponível em: https://bit. ly/3AlJCjC. Acesso em: 30 out. 2020.

CRUZ, T. M.; SANTOS, T. Z. Experiências escolares de estudantes trans. Reflexão e Ação, Santa Cruz do Sul, v. 24, n. 1, p. 115-137, 2016. Doi: http://dx.doi.org/10.17058/rea.v24i1.7041. Disponível em: https://bit.ly/2UP9Hr6. Acesso em: 30 out. 2020 .

DEUSDARÁ, B.; ROCHA, D.; ARANTES, P. C. C. Do Ethos ao Etos: um conceito sem $\mathrm{H}$ e sem determinantes. Cadernos de Estudos Linguísticos, Campinas, v. 61, e019020, p. 1-17, 2019. Doi: https://doi.org/10.20396/cel.v61i0.8655079. Disponível em: https://bit.ly/3jAbz19. Acesso em: 30 out. 2020 .

DIAS, G. J. P.; ARRUDA, M. O. G. R. Violentas e/ou Violentadas? travestis, violência e sofrimento ético-político. Revista FSA, Teresina, v. 18, n. 5, p. 179-196, 2021. Doi: http://dx.doi. org/10.12819/2021.18.5.11. Disponível em: https://bit.ly/3Ajf4zb. Acesso em: 18 jun. 2021.

DURÁN, L. A. A. Perfeccionismo y autoestima en escolares de Caracas. REINED: Revista Reflexión e Investigación Educacional, Chillán, v. 2, n. 2, p. 15-30, 2020. Disponível em: https://bit. ly/365UhkL. Acesso em: 30 out. 2020.

FEITOSA, C. Políticas públicas LGBT no Brasil: um estudo sobre o Centro Estadual de Combate à Homofobia de Pernambuco. Sexualidad, Salud y Sociedad, Rio de Janeiro, v. 32, n. 32, p.90-118, 2019. Doi: https://doi.org/10.1590/1984-6487. sess.2019.32.06.a. Disponível em: https://bit. 1y/2V2qTK5. Acesso em: 30 out. 2020.

FERREIRA, V; SACRAMENTO, I. Movimento LGBT no Brasil: violências, memórias e lutas. Revista Eletrônica de Comunicação, Informação e Inovação em Saúde, Rio de Janeiro, v. 13, n. 2, p. 234-239, 2019. Doi: https://doi.org/10.29397/ reciis.v13i2.1826. Disponível em: https://bit. ly/3h74p2S. Acesso em: 30 out. 2020.
FORMENTO, J. A. S.; ALMEIDA, S. S. Violência homofóbica: revisão sistemática da literatura. Research Society and Development, Itajubá, v. 9, n. 7, p. 1-15, 2020. Doi: http://dx.doi.org/10.33448/rsdv9i7.4939. Disponível em: https://bit.ly/3jzkBf6. Acesso em: 30 out. 2020.

GALRÃO, P. L.; CARVALHO, P. D. P. Violência nas margens: prostituição, abjeção e trans-gressões. Revista Debates Insubmissos, Caruaru, v. 3, n. 9, p. 2018-252, 2020. Doi: https://doi.org/10.32359/ debin2020.v3.n9.p218-252. Disponível em: https:// bit.ly/3dysoGc. Acesso em: 30 out. 2020.

GONÇALVES, H. C. B.; SCHMITT, G. M.; SILVA, J. D. I.; VIEIRA, R. S.; RIBEIRO, V.; COZAC, E. E. Os desafios e as estratégias de atendimento à população LGBT: um relato de experiência. Brazilian Journal of Development, São José dos Pinhais, v. 5, n. 12, p. 32896-32903, 2019. Doi: https:// doi.org/10.34117/bjdv5n12-346. Disponível em: https://bit.ly/3qEOE6w. Acesso em: 30 out. 2020.

GONÇALVES, M. V. G. S.; FRANCO, N. Olhares e abordagens sobre crianças trans. Journal Health NPEPS, Tangará da Serra, v. 4,n. 2, p. 405-422, 2019. Doi: http://dx.doi.org/10.30681/252610103870. Disponível em: https://bit.ly/363ILGF. Acesso em: 30 out. 2020.

GONZAGA, T. M. S.; GALlAS, A. K. C. O retrocesso no combate da lgbtfobia no Brasil: o preconceito vivenciado pela população LGBT no ambiente escolar. Filosofia e Educação, Campinas, v. 11, n. 2, p. 281-289, 2019. Doi: http://dx.doi. org/10.20396/rfe.v11i2.8655345. Disponível em: https://bit.ly/3Au5Tfs. Acesso em: 30 out. 2020.

GUALDA, G. L.; LACUNZA, A. B. Autoestima y habilidades sociales en niños y niñas del gran San Miguel de Tucumán, Argentina. Revista Argentina de Salud Pública, Buenos Aires, v. 11, n. 42, p. $22-$ 31, 2020. Disponível em: https://bit.ly/2TuFxsO. Acesso em: 30 out. 2020.

GUILHON, F.; SILVA JUNIOR. A. L.; MOTTA, C.; MOURA, A. D.; UZIEL, A. P. Centro de Cidadania LGBT: Memórias e Experiências no Campo das Práticas Psi em Prol da Defesa dos Direitos Humanos. Psicologia: Ciência e Profissão, Brasília, v. 39, n. 3, p. 135-145, 2019. Doi: https:// doi.org/10.1590/1982-3703003228604. Disponível em: https://bit.ly/366hjrD. Acesso em: 30 out. 2020. 
GUTIERRES, S. M.; LORDELLO, S. R. Promoção da saúde com transexuais e travestis: Uma revisão sistemática de literatura. Revista Psicologia Política, São Paulo, v. 20, n. 47, p. 165-177, 2020. Disponível em: https://bit.ly/2Tqzq94. Acesso em: 30 out. 2020.

HAMEL; M. R.; BOANOVA, A. M. S. A teoria do reconhecimento e a educação pública no cenário brasileiro. Revista Direitos Sociais e Políticas Públicas, Bebedouro, v. 8, n. 2, p. 173-196, 2020. Doi: http://dx.doi.org/10.25245/rdspp.v8i2.621. Disponível em: https://bit.ly/3y8QkYk. Acesso em: 30 out. 2020 .

HEISE, L.; GREENE, M. E.; OPPER, N.; STAVROPOULOU, M.; HARPER, C.; NASCIMENTO, M.; ZEWDIE, D. Gender inequality and restrictive gender norms: framing the challenges to health Lori Heise. The Lancet, London, v. 393, p. 2440-2454, 2019. Doi: https:// doi.org/10.1016/S0140-6736(19)30652-X. Disponível em: https://bit.ly/3Ag5xJ8. Acesso em: 30 out. 2020.

HONNETH, A. Luta por reconhecimento: a gramática moral dos conflitos sociais. São Paulo: Ed. 34, 2003.

JENNINGS, L.; BARCELOS, C.; MCWILLIAMS, C.; MALECKIA, K. Inequalities in lesbian, gay, bisexual, and transgender (LGBT) health and health care access and utilization in Wisconsin. Preventive Medicine Reports, New York, v. 14, p. 1-7, 2019. Doi: https://doi.org/10.1016/j.pmedr.2019.100864. Disponível em: https://bit.ly/3h8nqSA. Acesso em: 30 out. 2020.

JESUS, B. O.; VIEIRA, C. V. L.; RODRIGUES, A. A. Reconhecimento social e movimento feminista: caminhos para pensar uma sociedade mais justa? Revista PsicoFAE, Curitiba, v. 8, n. 1, p. 127-148, 2019. Disponível em: https://bit.ly/3haxwm8. Acesso em: 30 out. 2020.

KESSLER, M.; FACCHINI, L. A. Ações educativas e de promoção da saúde em equipes do Programa Nacional de Melhoria do Acesso e da Qualidade da Atenção Básica, Rio Grande do Sul, Brasil. Epidemiologia e Serviços de Saúde, Brasília, v. 27, n. 2, p. 1-12, 2018. Doi: https://doi.org/10.5123/ S1679-49742018000200019. Disponível em: https://bit.ly/3wcVrW2. Acesso em: 30 out. 2020.
KORPAISARN, S.; SAFER, J. D. Etiology of Gender Identity. Endocrinology and metabolism clinics of North America, Philadelphia, v. 48, n. 2, p. 323-329, 2019. Doi: https://doi.org/10.1016/j. ecl.2019.01.002. Disponível em: https://bit. ly/3heg7c6. Acesso em: 30 out. 2020.

LACERDA, P. J. C; LARA, L. M. O estado do conhecimento em políticas públicas de lazer como direito e reconhecimento social no Brasil. Licere, Belo Horizonte, v. 22, n. 3, p. 425-466, 2019. Doi: https://doi.org/10.35699/1981-3171.2019.15318. Disponível em: https://bit.ly/3wbwMRJ. Acesso em: 30 out. 2020.

LAZCANO, C. A Política do Nome Social na UFSC: reflexões sobre inclusão e cidadania. Cadernos de Gênero e Diversidade, Salvador, v. 6, n. 1, p. 154-180, 2020. Doi: http://dx.doi. org/10.9771/cgd.v6i1.35868. Disponível em: https://bit.ly/2UmVDEV. Acesso em: 30 out. 2020.

LOVISON, R.; LOVISON, R.; ASCARI, T. M.; ZOCCHE, D. A. A.; DURAND, M. K.; ASCARI, R. A. Travestis e transexuais: despindo as percepções acerca do acesso e assistência em saúde. Enfermagem em Foco, Brasília, v. 10, n. 5, p. 167172, 2019. Doi: http://dx.doi.org/10.21675/2357707X.2019.v10.n5.2370. Disponível em: https:// bit.ly/3xgUX2B. Acesso em: 30 out. 2020.

MACHADO, D. F.; GRAUPE, M. E.; LOCKS, G. A. Políticas Públicas LGBTTT e a Educação Avanços ou Retrocessos? Cadernos de Gênero e Diversidade, Salvador, v. 6, n. 4, p. 34-52, 2020. Doi: http://dx.doi.org/10.9771/cgd.v6i2.34847. Disponível em: https://bit.ly/3ha0iDc. Acesso em: 30 out. 2020.

MAGNO, L.; DOURADO, I.; SILVA, L. A. V. Estigma e resistência entre travestis e mulheres transexuais em Salvador, Bahia, Brasil. Cadernos de Saúde Pública, Rio de Janeiro, v. 34, n. 5, p. 1-12, 2018. Doi: https://doi.org/10.1590/0102311X00135917. Disponível em: https://bit. ly/3qKhTVK. Acesso em: 30 out. 2020.

MAGNO, L.; SILVA, L. A. V.; VERAS, M. A.; PEREIRA-SANTOS, M.; DOURADO, I. Estigma e discriminação relacionados à identidade de gênero e à vulnerabilidade ao HIV/aids entre mulheres transgênero: revisão sistemática. Cadernos de Saúde Pública, Rio de Janeiro, v. 35, v. 4, 
p. 1-21, 2019. Doi: https://doi.org/10.1590/0102311X00112718. Disponível em: https://bit. ly/3dzwJZt. Acesso em: 30 out. 2020.

MANCINI, L. A.; COSTA, M. L.; GUILEN, S. M. C. Cinema como experiência de lazer popular e inclusão social: uma experiência com pessoas idosas. Licere, Belo Horizonte, v. 23, n. 3, p. 618644, 2020. Doi: https://doi.org/10.35699/24476218.2020.25362. Disponível em: https://bit. ly/3hd8vXr. Acesso em: 30 out. 2020.

MEDEIROS, L. P.; AMORIM, A. K. M. A.; NOBRE, M. T. Narrativas LGBT de pessoas em situação de rua: repensando identidades, normas e objeções. Pesquisas e Práticas Psicossociais, São João Del-Rei, v. 15, n. 1, p. 1-16, 2020. Disponível em: https://bit.ly/3hrq44V. Acesso em: 30 out. 2020 .

MINAYO, M. C. S. Amostragem e saturação em pesquisa qualitativa: consensos e controvérsias. Revista Pesquisa Qualitativa, São Paulo, v. 5, n. 7, p. 1-12, 2017. Disponível em: https://bit. ly/3xfOvZB. Acesso em: 30 out. 2020.

MONTE, L. M. I.; NASCIMENTO, E. F. Eu sou assim, LGBT: solidariedade e direitos. Revista Espaço Acadêmico, Maringá, n. 221, p. 27-36, 2020. Disponível em: https://bit.ly/3y9uPa2. Acesso em: 30 out. 2020.

MONTEIRO, S. M. F.; GUIMARÃES, C. A. G. Abordagem clínica perante desequilíbrio da autoestima. Perspectivas em Psicologia, Uberlândia, v. 23, n. 2, p. 160-178, 2019. Disponível em: https://bit.ly/3 AydFVE. Acesso em: 30 out. 2020.

MORAES, A. N. D.; SILVA, G. S. N. Travestis e o cuidado humanizado em saúde. Revista da Abordagem Gestáltica, Goiânia, v. 16, n. 2, p. 175187, 2020. Doi: http://dx.doi.org/10.18065/2020 v26n2.5. Disponível em: https://bit.ly/36bjQRA. Acesso em: 30 out. 2020.

MUGABE, N. Marcadores sociais da diferença e sentimentos no universo LGBT maputense. Cadernos de Campo, São Paulo, v. 28, n. 2, p. 306-324, 2019. Doi: https://doi.org/10.11606/ issn.2316-9133.v28i2p306-324. Disponível em: https://bit.ly/2UTlTHk. Acesso em: 30 out. 2020.
NAGAMINE, R. V. V. K. Os direitos de pessoas LGBT na ONU (2000-2016). Sexualidad, Salud $y$ Sociedad, Rio de Janeiro, n. 31, p. 28-56, 2019. Doi: https://doi.org/10.1590/1984-6487. sess.2019.31.03.a. Disponível em: https://bit. 1y/2TvT8A7. Acesso em: 30 out. 2020.

OLIVEIRA, E. M.; OLIVEIRA, J. F.; SUTO, C. S. S.; PORCINO, C.; ALMEIDA, S. P.; OLIVEIRA, D. S. Espaços institucionais de saúde como "não lugar" de travestis nas representações sociais de enfermeiras. Revista Baiana de Enfermagem, Salvador, v. 34, e35603, p. 1-11, 2020. Doi: http:// dx.doi.org/10.18471/rbe.v34.35603. Disponível em: https://bit.ly/3dFvUyB. Acesso em: 30 out. 2020 .

OSORIO, J. F. R.; GÓMEZ, C. A. Acoso escolar contra jóvenes LGBT e implicaciones desde una perspectiva de salud. Salud UIS, Bucaramanga, v. 52, n. 2, p. 147-151, 2020. Doi: http://dx.doi. org/10.18273/revsal.v52n2-2020008. Disponível em: https://bit.ly/3jB7UQX. Acesso em: 30 out. 2020 .

PAULINO, D. B.; RASERA, E. F.; TEIXEIRA, F. B. Discursos sobre o cuidado em saúde de Lésbicas, Gays, Bissexuais, Travestis, Transexuais (LGBT) entre médicas(os) da Estratégia Saúde da Família. Interface (Botucatu), Botucatu, v. 23, e180279, p. 1-15, 2019. Doi: https://doi.org/ 10.1590/Interface.180279. Disponível em: https:// bit.ly/3wihFGi. Acesso em: 30 out. 2020.

PELÚCIO, L. Toda Quebrada na Plástica: Corporalidade e construção de gênero entre travestis paulistas. Campos: Revista de Antropologia, v. 6, p. $97-$ 112, 2005. Doi: http://dx.doi.org/10.5380/cam. v6i0.4509. Disponível em: https://bit.ly/2TvUFpR. Acesso em: 30 out. 2020.

PEREIRA, M. M. Trazendo os governos de volta: a chefia do executivo e os resultados do ativismo institucional LGBT (2003-2014). Sociologias, Porto Alegre, v. 22, n. 53, p. 228-263, 2020. Doi: https:// doi.org/10.1590/15174522-95594. Disponível em: https://bit.ly/3hwnf2A. Acesso em: 30 out. 2020.

PETERMANN, X. B.; KOCOUREK, S. Análise da produção científica sobre a Política Nacional de Promoção da Saúde no Brasil: um estudo bibliométrico na Biblioteca Virtual em Saúde. Saúde (Santa Maria), Santa Maria, v. 46, n. 1, p. 1-12, 2020. 
Doi: https://doi.org/10.5902/2236583441957. Disponível em: https://bit.ly/3qGvk95. Acesso em: 30 out. 2020 .

PIRATELLI FILHO, M. B.; SODA, M. E. I.; ANTUNES, M. B.; ALMEIDA, C. R.; BOLSONI, L. L. M.; OLIVEIRA, W. T.; CHARLO, P. B. Investigação sobre a assistência prestada à população LGBTQ+ na atenção primária de saúde. Saúde Coletiva, Barueri, v. 9, n. 49, p. 1519-1525, 2019. Disponível em: https://bit.ly/3jHaUvb. Acesso em: 30 out. 2020.

PONTES, H.; ROSATTI, C. G.; REIS, E. T. Gênero e cultura nas ciências sociais brasileiras: depoimento de uma pesquisadora com nome próprio. Repocs, São Luís, v. 17, n. 34, p. 101128, 2020. Doi: http://dx.doi.org/10.18764/22369473.v17n34p101-128. Disponível em: https://bit. ly/2TBqVYR. Acesso em: 30 out. 2020.

PRETO, V. A.; FERNANDES, J. M.; SILVA, L. P.; REIS, J. O. L.; SOUSA, B. O. P.; PEREIRA, S. S.; SAILER, G. C.; CARDOSO, L. Transtornos Mentais Comuns, Estresse e Autoestima em universitários da área da saúde do último ano. Research, Society and Development, Itajubá, v. 9, n. 8, e844986362, 2020. Doi: http://dx.doi.org/10. 33448/rsd-v9i8.6362. Disponível em: https://bit. ly/3wgguXT. Acesso em: 30 out. 2020.

QUADRADO, J. C.; FERREIRA, E. S. Os (des) caminhos da política pública de assistência social no atendimento à população LGBT. Humanidades e Inovação, Palmas, v. 6, n. 17, 2019. Disponível em: https://bit.ly/3hEyoOK. Acesso em: 30 out. 2020.

RO, H.; OLSON, E. D. Gay and lesbian customers' perceived discrimination and identity management. International Journal of Hospitality Management, Oxford, v. 84, n. 102319, p. 1-9, 2020. Doi: https:// doi.org/10.1016/j.ijhm.2019.102319. Disponível em: https://bit.ly/2TuH9TJ. Acesso em: 30 out. 2020.

ROSA, D. F.; CARVALHO, M. V. F.; PEREIRA, N. R.; ROCHA, N. T.; NEVES, V. R.; ROSA, A. S. Assistência de Enfermagem à população trans: gêneros na perspectiva da prática profissional. Revista Brasileira de Enfermagem, Brasília, v. 72, Suppl. 1, p. 311-319, 2019. Doi: http://dx.doi. org/10.1590/0034-7167-2017-0644. Disponível em: https://bit.ly/3ysf0LU.Acesso em: 30 out. 2020.
ROSENKRANTZ, D. E.; ROSTOSKY, S. S.; TOLAND, M. D.; DUEBER, D. M. Cognitiveaffective and religious values associated with parental acceptance of an LGBT child. Psychology of Sexual Orientation and Gender Diversity, Washington, v. 7, n. 1, p. 55-65, 2020. Doi: https://bit.ly/3jOs4a6. Disponível em: https://bit. ly/3yoH9Dl. Acesso em: 30 out. 2020.

ROVAI, M. G. O. "Que Possamos Ser o que Somos": memórias sobre o Movimento Gay de Alfenas no processo de luta pelos direitos de cidadania LGBT (2000-2018). Anos 90, Porto Alegre, v. 26, e2019303, p. 1-20, 2019. Doi: https:// doi.org/10.22456/1983-201X.89951. Disponível em: https://bit.ly/3dKeMYC. Acesso em: 30 out. 2020.

SANTOS FILHO, F. R. M.; SOUSA, M. L. T. Implicações ético política do corpo travesti nas políticas de saúde ethical-political. Sanare, Sobral, v. 16, n. 1, p. 48-57, 2017. Disponível em: https:// bit.ly/3 AxdHNi. Acesso em: 30 out. 2020.

SANTOS, K. E. S.; JESUS, C. D. Prevalence of Bullying among LGBT Students in Nueva Ecija. Scientific Research Publishing, Wuhan, v. 7, n. 2, p. 1-7, 2020. Doi: https://doi.org/10.4236/oalib. 1106066. Disponível em: https://bit.ly/2V4GgRX. Acesso em: 30 out. 2020.

SANTOS, M. S.; MORALES, S. D. C. Sala de recursos multifuncionais - surdez: lugar de aprendizagem, autoestima e interação. Brazilian Journal of Development, São José dos Pinhais, v. 6 , n. 7, p. 43024-43037, 2020. Doi: https://doi. org/10.34117/bjdv6n7-063. Disponível em: https:// bit.ly/3qPtsut. Acesso em: 30 out. 2020.

SANTOS, T. F. S.; MARTINELli, M. L. A sociabilidade das pessoas travestis e transexuais na perícia social. Serviço Social \& Sociedade, Rio de Janeiro, n. 134, p. 142-160, 2019. Doi: https:// doi.org/10.1590/0101-6628.170. Disponível em: https://bit.ly/3ysu2kr. Acesso em: 30 out. 2020.

SANTOS, T. V.; MOREIRA; M. C. N.; GOMES; R. Performance e deficiência: caminhos para reinvenção da saúde. Ciência \& Saúde Coletiva, Rio de Janeiro, v. 25, n. 8, p. 3143-3152, 2020. Doi: https:// doi.org/10.1590/1413-81232020258.28292018. Disponível em: https://bit.ly/3hvfdHa. Acesso em: 30 out. 2020. 
SCHOEPS, K.; TAMARIT, A.; GONZÁLEZ, R.; MONTOYA-CASTILLA, I. Competencias emocionales y autoestima en la adolescencia: impacto sobre el ajuste psicológico. Revista de Psicología Clínica con Niños y Adolescentes, Valencia, v. 6, n. 1, p. 51-56, 2019. Doi: https://doi.org/10.21134/ rpcna.2019.06.1.7. Disponível em: https://bit. 1y/3wdGWBn. Acesso em: 30 out. 2020.

SCOTT, J. Gênero: uma categoria útil para análise histórica. Educação \& Realidade, Porto Alegre, v. 16, n. 2, p. 5-22, 1990. Disponível em: https:// bit.ly/3hF2At2. Acesso em: 30 out. 2020.

SILVA, A. C. A.; ALCÂNTARA, A. M.; OLIVEIRA, D. C.; SIGNORELLI, M. C. Implementação da Política Nacional de Saúde Integral de Lésbicas, Gays, Bissexuais, Travestis e Transexuais (PNSI LGBT) no Paraná, Brasil. Interface: Comunicação, Saúde, Educação, Botucatu, v. 24, e190568, p. 1-15, 2020. Doi: https://doi.org/10.1590/Interface.190568. Disponível em: https://bit.ly/3qQMX6e. Acesso em: 30 out. 2020 .

SILVA, A. O. G. O Nome Social enquanto Política Pública nas Universidades Estaduais do Paraná. Cadernos de Gênero e Diversidade, Salvador, v. 5, n. 2, p. 14-39, 2019. Doi: http://dx.doi.org/10.9771/cgd. v5i2.26664. Disponível em: https://bit.ly/3yjaoHE. Acesso em: 30 out. 2020.

SILVA, B. B.; SANTOS, E. C. Apoio social na autoestima e identidade social de pessoas trans brasileiras. Psico, Porto Alegre, v. 49, n. 4, p. 422432, 2018. Doi: https://doi.org/10.15448/19808623.2018.4.30029. Disponível em: https://bit. ly/3qNXwGZ. Acesso em: 30 out. 2020.

SILVA, L. C. X.; ISAYAMA, H. F. Uma análise das políticas públicas de lazer para a população LGBT em Belo Horizonte. Motrivivência, Florianópolis, v. 32, n. 63, p. 01-24, 2020. Doi: https://doi.org/ 10.5007/2175-8042.2020e71549. Disponível em: https://bit.ly/3jGAPmE. Acesso em: 30 out. 2020.

SILVA, M. E. F.; BRABO, T. S. A. M.; SHIMIZU, A. M. Avanços e retrocessos nas políticas públicas educacionais contemporâneas: censuras e supressões referentes a gênero e sexualidades em documentos oficiais de educação (1997-2015). Educação em Debate, Fortaleza, v. 41, n. 80, p. 93110, 2019. Disponível em: https://bit.ly/2TuV500. Acesso em: 30 out. 2020.
SILVA, M. E. F.; MACIEL, T. S.; BRABO, T. S. A. M. Direitos humanos das mulheres e das pessoas LGBT: a relação agridoce entre gênero e educação em meio a desafios contemporâneos. Interfaces Cientificas, Aracajú, v. 7, n. 2, p. 157168, 2019. Doi: https://doi.org/10.17564/23163828.2019v7n2p157\%E2\%80\%93168. Disponível em: https://bit.ly/3wihJWD. Acesso em: 30 out. 2020.

SOUZA, A. K. C. ; PEREIRA, J. R.; TORRES, T. P. R.; BARATA, J. G. "Bota a cara no sol": o silêncio e a resistência na empregabilidade LGBT. Revista Horizontes Interdisciplinares da Gestão, Belo Horizonte, v. 4, n. 1, p. 1-22, 2020. Disponível em: https://bit.ly/3ysqT47. Acesso em: 30 out. 2020.

SOUZA, M. B. C. A.; HELAL, D. H. Política nacional de saúde integral de lésbicas, gays, bissexuais, travestis e transexuais: análise descritiva e utilização de dados secundários para pesquisa e prática. $B A G O A S$, Natal, v. 9, n. 13, p. 221251, 2015. Disponível em: https://bit.ly/3AFlo4i. Acesso em: 30 out. 2020.

SOUZA, M.; PRADO, M. O. Violências, mulheres travestis, mulheres trans: problematizando binarismos, hierarquias e naturalizações. Revista Polis e Psique, Porto Alegre, v. 9, n. 2, p. 45-66, 2019. Doi: https://doi.org/10.22456/2238-152X.83831. Disponível em: https://bit.ly/2TFL0Nz. Acesso em: 30 out. 2020.

STARKI, M.; AMIN, M. M. Depression on transvestites towards community acceptance based on demographics, principles and beliefs at the deli serdang, Medan. Open Access Macedonian Journal of Medical Sciences, Macedonia, v. 7, n. 16, p. 2688-2690, 2019. Doi: https://doi.org/10.3889/ oamjms.2019.412. Disponível em: https://bit. ly/3jGyc4g. Acesso em: 30 out. 2020.

STEVENS, S.; HAVERLY, K.; POWELL, C. C. Improvements in Self-Acceptance for LGBTQ+ and Straight Allied Youth and Young Adults Enrolled in an Affirming System of Care Program. Children and Youth Services Review, New York, v. 118, e105382, 2020. Doi: https://doi. org/10.1016/j.childyouth.2020.105382. Disponível em: https://bit.ly/3wdEkDz. Acesso em: 30 out. 2020 . 
SWAIN, K. No matter what pronoun: reading on gender and humanity. The Lancet Child \& Adolescent Health, London, v. 3, n. 9, p. 603604, 2019. Doi: https://doi.org/10.1016/S23524642(19)30232-9. Disponível em: https://bit. ly/3hdU18q. Acesso em: 30 out. 2020.

TAGLIATE, A. D. S.; FRANCO, N. Travestis vivendo com HIV/AIDS e seus determinantes sociais: antes e depois do diagnóstico. Revista Brasileira de Pesquisa (Auto)biográfica, Salvador, v. 5, n. 13, p. 419-435, 2020. Doi: http://dx.doi. org/10.31892/rbpab2525-426X.2020.v5.n13. p419-435. Disponível em: https://bit.ly/3hFC56X. Acesso em: 30 out. 2020.

TEIXEIRA, G. L.; PORÉM, M. E. Travestis e organizações: o papel da comunicação na construção de espaços organizacionais. Revista Eletrônica de Comunicação, Informação e Inovação em saúde, Rio de Janeiro, v. 13, n. 2, p. 301-313, 2019. Doi: https://doi.org/10.29397/reciis.v13i2.1704. Disponível em: https://bit.ly/3yZuA1R. Acesso em: 28 out. 2020.

VEIGA, L. F.; ROMANINI, M. Armário de vidro: (re)conhecendo as políticas públicas e os direitos sexuais da população LGBT. Psicologia Argumento, Curitiba, v. 35, n. 89, p. 1-22, 2017. Doi: http:// dx.doi.org/10.7213/psicol.argum.35.89.AO03. Disponível em: https://bit.ly/3AngwAu. Acesso em: 30 out. 2020 .

VENTURA, C. A.; FUMINCELLI, L.; MIWA, M. J.; SOUZA, M. C.; WRIGHT, M. G. M.; MENDES, I. A. C. Advocacia em saúde e atenção primária à saúde: evidências para enfermagem. Revista Brasileira de Enfermagem, Brasília, v. 73, n. 3, p. 1-8, 2020. Doi: https://doi. org/10.1590/0034-7167-2018-0987. Disponível em: https://bit.ly/3jKNAfO. Acesso em: 30 out. 2020 .

VOSVICK, M.; STEM, W. Psychological quality of life in a lesbian, gay, bissexual, transgender sample: correlates of stress, mindful acceptance, and self-esteem. Psychology of Sexual Orientation and Gender Diversity, Washington, v. 6, n. 1, p. 3441, 2019. Doi: https://doi.org/10.1037/sgd0000303. Disponível em: https://bit.ly/3jFXbol. Acesso em: 30 out. 2020.
WEDIG, J. C.; WALlAU, A. S.; PADILHA, A. F.; SIMONETT, A. L. Sociabilidade e lazer entre mulheres camponesas: vivências no clube de mães. Licere, Belo Horizonte, v. 23, n. 2, p. 58-81, 2020. Doi:https://doi.org/10.35699/2447-6218.2020.21784. Disponível em: https://bit.ly/3ADRDAX. Acesso em: 30 out. 2020 .

YEUNG, H.; LUK, K. M.; CHEN, S. C.; GINSBERG, B.; KATZ, K. A. Dermatologic care for lesbian, gay, bissexual, and transgender persons: Terminology, demographics, health disparities, and approaches to care. Journal of the American Academy of Dermatology, Saint Louis, v. 80, n. 3, p. 581-589, 2019. Doi: http://dx.doi.org/10.1016/j. jaad.2018.02.042. Disponível em: https://bit. ly/3wd5dI1. Acesso em: 30 out. 2020.

ZANI, L. F.; TERRA, M. F. Conhecimentos sobre identidade de gênero e orientação sexual entre graduandos/as de enfermagem. Journal Health NPEPS, Tangará da Serra, v. 4, n. 2, p. 167-179, 2019.Doi:http://dx.doi.org/10.30681/252610103649. Disponível em: https://bit.ly/2TAqHBf. Acesso em: 30 out. 2020.
Recebido em: 1 jan. 2021

Aceito em: 22 jun. 2021 
Moraes, L. E. S. et al. 